\title{
Obesity, Unemployment, and Earnings
}

\section{Juho Härkönen}

Docent, SOFI, Stockholm University, Sweden

\section{Pekka Räsänen}

Professor, Department of Social Research, University of Turku, Finland

\section{Matti Näsi}

Researcher, Department of Social Research, University of Turku, Finland

\begin{abstract}
The article analyses the effects of obesity — a clear signal of weight abnormality — on unemployment and earnings among Finnish men and women. Our empirical data consist of the last four waves (waves 4 to 8) of the Finnish section of the European Community Household Panel (ECHP) data collected between 1998 and 200I. According to our results, obese women have a significantly higher risk of unemployment (even after controlling for age, level of education and other related factors), than women who are not obese. Furthermore, the generally weaker occupational positions of obese women tend to translate to lower earnings. Overall, obese women are more likely to have weaker labour market attachment and hold socio-economically weaker positions. Similar results were not found among men. Thus, our results indicate the presence of gender discrimination in the Finnish labour market. In the conclusions we further discuss weight related impacts on succeeding in the labour market, but also its role as a possible risk factor in drifting away from employment. We reflect on this issue as a form of inequality that can have an increasing significance in the future.
\end{abstract}

\section{KEY WORDS}

Weight / obesity / labour market / income / societal inequality / gender.

\section{Introduction}

fter decades of abundance in Western societies, lifestyle diseases are not a particularly new phenomenon as weight related health problems have become a visible part of many of these societies over the last two decades. The World Health Organization (WHO) estimated that the number of overweight people has doubled in most European countries over the past decade. (WHO 2003, 4-5, 61-62). Excess weight gain is no longer a concern associated only with middle-agers; these days it is a growing problem among children and young adults as well. Finland makes no exception to these trends.

In the past few years obesity has been a frequent topic of discussion in Finnish media outlets and research literature, both in the health and social sciences. Most of the research in the social sciences has focused on the effects of obesity on quality of life. (e.g. Harjunen

Juho Härkönen, Docent, Swedish Institute for Social Research, Stockholm University, Sweden.

E-mail: juho.harkonen@sofi.su.se 
2004; Jokinen 1997; Puuronen 2004). As a result, obesity related research tends to have a somewhat negative tone. According to Oswald \& Powdthavee (2007), overweight and obese people tend to feel that they are treated differently and posses lower self-esteem than people who are normal weight. Other results pointing to adverse effects of obesity can be found in the sociology of health and social medicine, according to which obese people suffer more from psychological and physiological illnesses than people who are normal weight (e.g. Pietinen et al. 1996; Lallukka et al. 2005; Sarlio-Lähteenkorva \& Lahelma 1999). Furthermore, obesity is also related to adult diabetes, blood and heart diseases and shorter life expectancy (WHO 2003; Conley \& Bennett 2000; Laitinen et al. 2002).

The current research literature points out that weight and self image seem to have a strong connection with gender, and women tend to experience more appearance related pressures than men. Slender physical appearance is usually a way to seek social approval. Research focused on subjective self-evaluation of one's physical appearance indicates that change in body weight tends to be societally more acceptable for men than for women. (e.g. Gossrow et al. 2001; see also: Harjunen 2004; Schmitt $\&$ Buss 1996; Rooth 2009). Societal pressure to be thin is thus stronger towards women than men.

Relatively little research in Finland has focused on the connection between obesity, socio-demographic living conditions and earnings (however, see Sarlio-Lähteenkorva \& Lahelma 1999; Sarlio-Lähteenkorva et al. 2004). However, one can expect obesity to influence not only people's general subjective views, but also socio-economic outcomes. Does weight influence how well one does in the labour market? Does it have the same impact on men than it does on women? What specific factors does it affect? Does obesity have a cumulative influence on social deprivation after controlling for the more traditional socio-economic background factors?

In this article we examine the impact of obesity on unemployment and earnings among Finnish men and women. Finland can be considered as an important research context since the Nordic countries are generally devoted to full employment of both men and women. In addition, income differences between men and women are relatively small in Finland compared to most other countries. More specifically, our research topic was chosen on the following basis: First, employment and earnings are core labour market outcomes. Second, following these, if the risk of unemployment is higher than average among obese people, ceteris paribus, it can reflect discrimination in the labour market (e.g. Garcia \& Quintana-Domeque 2006).

The article is structured as follows. In the first part we conduct a short overview of BMI as an indicator used in weight related research and examine recent changes in the proportion of overweight and obese people in Finland. After that, we explore some of the main differences between population groups as well as examine previous research on obesity and labour market success. In the second part of the article, we will introduce the research problem, the data and the methodology. Our empirical data consist of the European Community Household Panel's (ECHP) Finnish subsample and covers the years 1998 to 2001. In the conclusion we discuss the impacts of obesity on labour market success, as well as the potential risk of labour market exclusion. Furthermore, we introduce some structural frameworks that can help focus future research on weight related studies and this way better serve current welfare policies. 


\section{Body Mass Index (BMI) and weight differences between different population groups}

Body Mass Index (BMI) is the most commonly used tool in analyzing body weight. BMI is calculated by dividing weight $(\mathrm{kg})$ with the square root of height $(\mathrm{m})=\left(\mathrm{kg} / \mathrm{m}^{2}\right)$. Although easily measured, BMI is just one indicator of body weight and correspondingly, of obesity. Other commonly used indicators include fat mass and weight circumference. Johansson and associates (2009) reported that different measures can lead to different results concerning labour market penalties associated with excess weight (although, importantly for our study, they found that all of their measures of obesity were associated with women's employment). In any case, high BMI can be considered a good measure of high body weight readily observed by employers and other actors, who may use body weight as a signal for (un)desirable worker characteristics or as a basis for discrimination.

Adult BMI is commonly categorized in the following way: 1) Lower than average weight, (18,4 or under), 2) Average weight (18,5-24,9), 3) Overweight (25,0-29,9), 4) Obese Class I $(30,0-34,9), 5)$ Obese Class II $(35,0-39,9), 6)$ Obese Class III $(40 \geq)$ (e.g. Lahti-Koski 2001, 13-15). However, it is important to emphasize that overarching definitions of obesity do not exist. For instance, children, elderly people and professional athletes tend to have a different ideal BMI than other population groups. As a clarification, throughout this paper we use the term overweight both as a description of excess weight of BMI 25,0-29,9. The term obesity is used to describe BMI above 30 (Obese Class 1-3).

Estimations of the number of overweight and obese people vary depending on the calculation method. But in terms of the data analysis, we use the standard WHO categories to ensure commonly used categorization. So, if we use normal weight as the comparison point, almost half of the Finnish population (15 years and older) can be deemed overweight. In fact according to most recent official statistics, almost 49 per cent of Finns (15 years and older) are deemed overweight (OECD 2005; WHO 2010), and nearly 16 per cent are classified as obese. In Finland men tend to be more overweight, whereas relatively more women suffer from more severe forms of obesity.

Figures 1 and 2 represent overweight and obesity trends in Finland in the last two decades. The data has been collected from the WHO international database and it appears to be similar to most other estimations (e.g. Pietinen et al. 1996; Lahti-Koski 2001).

Figure 1 indicates that the number of overweight people in Finland has grown steadily since the beginning on 1990's. By 2008 almost 49 per cent of Finns could be classified as overweight, when in the early 1990's the same number was less than 40 per cent. On the other hand, Figure 2 indicates the number of more severely obese Finns did not start to rise until the turn of the millenium.

These figures show clearly that obesity is increasing in Finland. There are various explanations for this trend. It is clear that diet and life-style are directly connected with body weight. An unhealthy diet that includes excessive amounts of fat and calories combined with lack of proper exercise largely explains the current situation. Furthermore, metabolism, growth development in childhood and different eating disorders can contribute to the increasing trend over past two decades. (Lallukka et al. 2005, 909; 
Figure I: Percentage of Overweigh people in Finland 1992-2008. (source: WHO Global Database on Body Mass Index (WHO 2010)

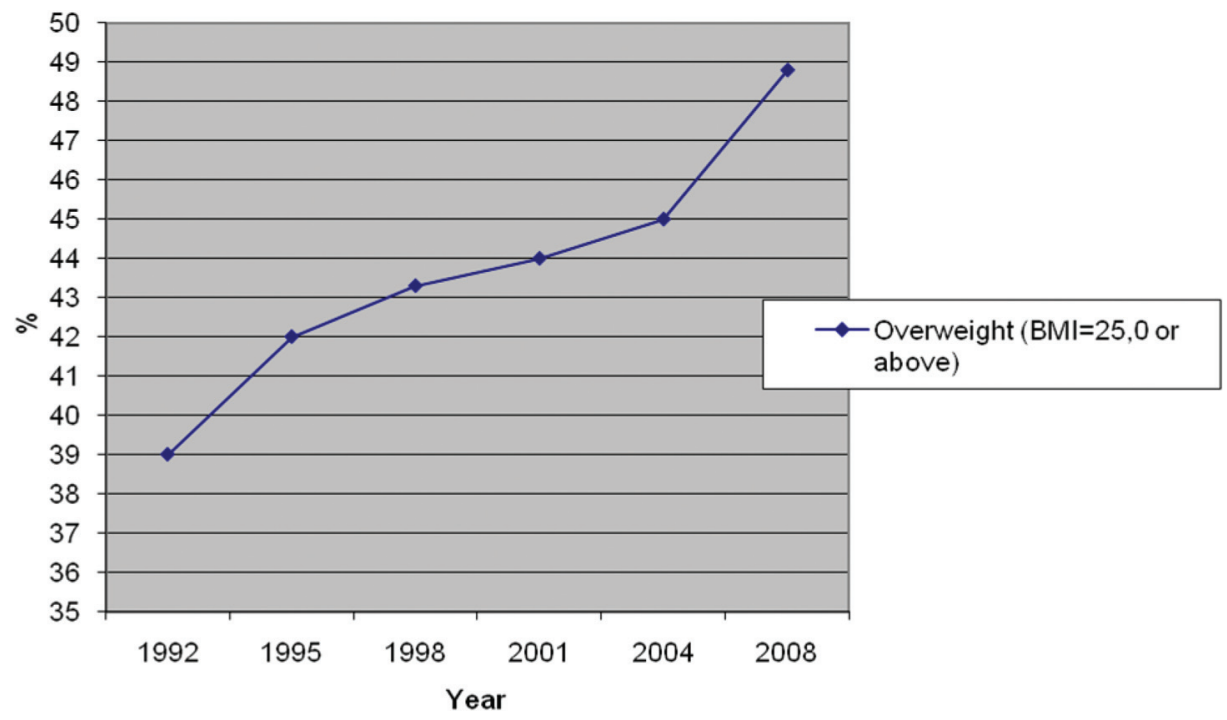

Figure 2: Percentage of Obese people in Finland 1992-2008. (source: WHO Global Database on Body Mass Index (WHO 2010)

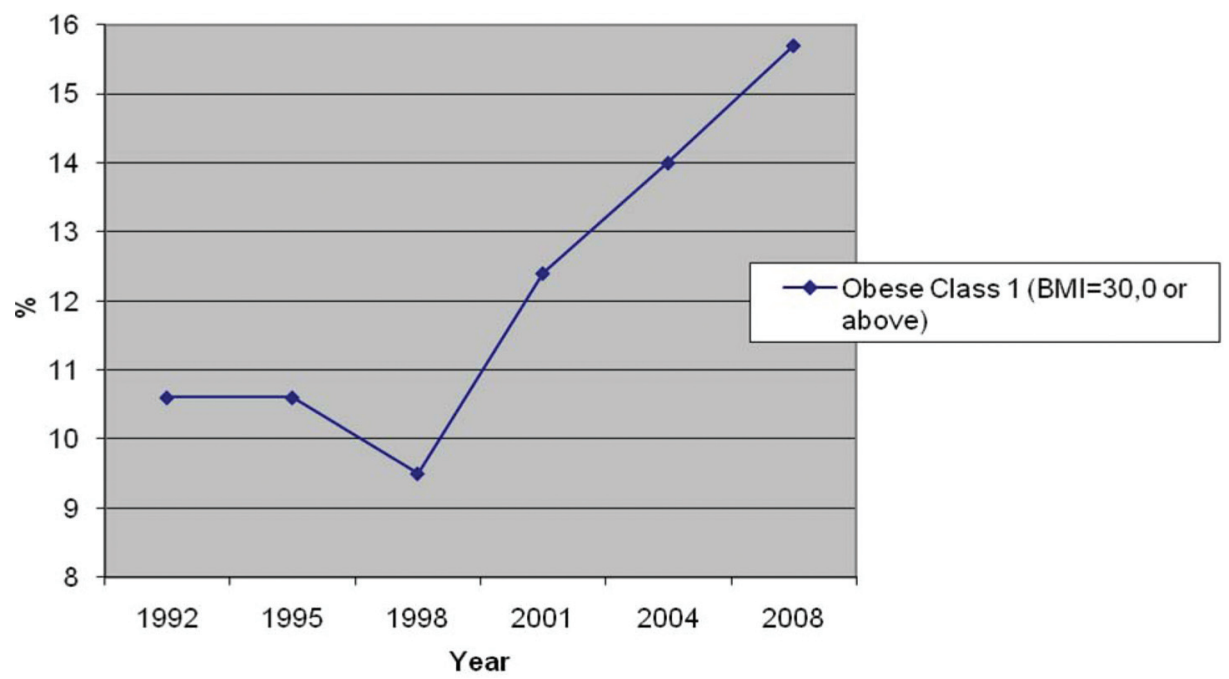

Conley \& Bennett 2000, 458-459). Increases in obesity are not only related to period change, but each successive cohort has been more obese than previous ones (for the US see Reitner et al. 2009).

From a sociological perspective, studies that focus on variation between different population groups are particularly interesting. In light of previous studies, age, gen- 
der, education, earnings and marital status are all known to be connected to obesity (e.g. Conley \& Glauber 2007; Lahti-Koski 2001; Laitinen et al. 2002). For instance, overweight people are more often single (marital status), but those who get married, get divorced more often than people of average weight (Lahti-Koski 2001, 34-37; Conley \& Glauber 2007, 271).

Middle-aged people in Finland are more likely to be obese than other age groups. Gender is another defining factor as obesity is more common among young females, whereas more middle aged men suffer from obesity than women. The existing literature indicates that gender differences can be partially explained by different roles within the family (e.g. Conley \& Bennett 2000; Conley \& Glauber 2007). According to the literature, some of these mechanisms are biological; pregnancy, for instance, usually leads to weight gain that does not generally stabilize until two years after birth. The unequal share of domestic duties and the resulting lack of leisure time can also explain higher obesity among younger women in comparison to men. Besides this, there is a variety of different hypotheses explaining weight gain in later life. For instance, general interest and enthusiasm towards exercise tend to decrease with age, resulting in increasing weight gain, especially among middle aged men.

Even though researchers have established a connection between unemployment, education and obesity (e.g. Pietinen et al. 1996; Oswald \& Powdthavee 2007), the relationship between education and obesity is not linear (e.g. Conley \& Glauber 2007; Sarli-Lähteenkorva \& Lahelma 1999). However, according to Glass and associates, (2010) overweight women tend to have less post-secondary education than women of normal weight, thus influencing their occupational status in the labour market. These results are often dependent on the obesity related criteria that any given research project uses. However, similar results were found from a study that conducted similar comparisons between different professions (Laitinen et al. 2002, 1332-1333).

The effects of obesity on labour market success are shaped by gender. For instance, the connection between unemployment and obesity has generally only been found among women, not among men (e.g. Sarlio-Lähteenkorva \& Lahelma 1999, 448; Oswald \& Powdthavee 2007). Thus, taking gender into account is necessary when making any kind of socio-economic comparisons. In the following sections we will analyse the connection between obesity and success in the employment sector in more detail.

\section{Obesity and labour market success}

There are at least three possible factors connecting unemployment and earnings with obesity. These are 1) Causal effect of obesity on labour market outcomes 2) Reverse causality, and 3) Factors related to both (cf. Garcia \& Quintana-Domeque 2006). Firstly, there might be a direct causal connection between obesity and labour market outcomes. For instance, excess weight might decrease one's level of productivity. Following human capital theory (e.g. Mincer 1974; Becker 1975), there is less demand for less productive employees who are also generally offered less salary.

Employers may also discriminate overweight candidates. Certain professions may have appearance related requirements and excess weight is not viewed as a desired fea- 
ture. There may be variety of different reasons why some employers discriminate against overweight people (Carr \& Friedman 2005; Smith \& Buss 1996). There is evidence that some overweight people are selected, either knowingly or unknowingly, for different types of jobs than those of normal weight. For instance, Pagán and Dávila (1997) discovered that overweight men tend to select to jobs where obesity was not a disadvantage. According to the same study, the reason why overweight women were less successful in finding employment was mostly due to discrimination on behalf of employers. A similar conclusion was drawn by Härkönen (2008), who found that obese women in Finland are no more likely to exit employment, but have more difficulties in finding work even as their job search behaviours do not differ from their non-obese peers. Pagan and Dávila (1997) also speculated that there is a negative connection between obesity and self-control. Even if this would not have anything to do with reality, beliefs of this kind may affect employers' recruitment decisions.

Secondly, income level and occupation may partially explain obesity, as poor living conditions do not necessary cater for a healthy diet and lifestyle. Thirdly, factors such as age and education predict both obesity and labour market success. Various of Finnish consumption surveys reveal that families where parent(s) work in manual labour occupations tend to eat more ready-made meals compared to white collar families. (e.g. Toivonen 1997; Räsänen 2003). Besides this, manual labour families have lower income and a higher unemployment risk.

Previous research supports the assumption that obesity related effects are largely dependent on gender. Overweight women are paid less and suffer from higher unemployment risk, whereas similarly clear effects among men are usually not found (e.g. Pagán \& Dávila 1997; Cawley 2004; Sarlio-Lähteenkorva et al. 2004; Garcia \& QuintanaDomeque 2006). However, Brunello \& D’Hombres (2007) found evidence that increase in BMI had a weak negative effect on the earnings of both men and women in wider European perspective. Furthermore, Cawley (2004) estimated, based on data collected in the US, that approximately 30 kilograms increase in weight (for women) equalled 9 per cent decrease in salary. As a comparison, this equals 1.5 years in education or 3 years work experience.

According to Sarlio-Lähteenkorva and Lahelma (Sarlio-Lähteenkorva \& Lahelma 1999; Sarlio-Lähteenkorva et al. 2004), overweight women tend to suffer from a higher unemployment risk (Härkönen 2008) and lower salary level. Their results also indicated that the negative impact of obesity was particularly strong in higher socioeconomic groups (Sarlio-Lähteenkorva et al. 2004). These findings are in line with similar international studies (see also, Garcia \& Quintana-Domeque 2006). Interestingly, Johansson and colleagues (2007) found differing results of the effects of obesity on labour market outcomes, depending on the measure used. All obesity measures were related to lower employment among women, whereas high fat mass and high waist circumference predicted lower employment of men. For wages, the results were less robust.

\section{Research questions, data, and methods}

Our empirical analysis focuses on two important labour market outcomes, unemployment and earnings. Our objective is to analyse whether obesity affects these two out- 
comes, and whether these effects vary by gender. Thus, our empirical research questions are the following:

1) Does obesity influence unemployment and earnings in Finland?

2) To what extend are any observed effects gender related?

3) Are the effects robust after adjusting for confounding factors?

Our data consist of the last four waves (from 1998 to 2001) of the Finnish European Community Household Panel (ECHP) survey. The ECHP includes up to eight annual waves of follow-up information on individuals and their households. The individual files include information on all household members aged 16 or above. The first wave of the Finnish sample was collected in 1996 (with a response rate of 73.3\%) and the total Finnish sample includes six waves. Information on height and weight was collected only in the last four waves; hence the decision to restrict the analysis only to these waves (from 1998 to 2001).

We further restricted our analysis to prime working age, 25 to 54 year old, respondents who were active in the labour market (were either employed or unemployed [looking for work]). We also excluded the self-employed and farmers, thus focusing on those who offer their labour to employers. After these restrictions, our data consisted of 4,159 participants (the total number of respondents varies somewhat in the regression analyses due to a small number of missing cases, the exclusion of which did not affect our results). In the descriptive analysis we used sample weights (Tables 1 and 2). In the regression analyses this was unnecessary given that the variables used to construct the weights are included as explanatory variables (cf., Winship \& Radbill 1994). As all panel data, the ECHP suffers from panel attrition. Although this attrition is not random, it generally does not affect substantive conclusions in labour market studies (Behr et al. 2005; Härkönen 2003).

Our independent variables are a) unemployment, and b) logged gross monthly earnings, following the two labour market outcomes we are interested in. Unemployment was measured using a simple employed - unemployed binary variable. Given that we focus on those currently active in the labour market (and excluding homemakers, students, and the like), this specification measures difficulties in finding work despite active search efforts, thus corresponding to the ILO definition of unemployment (e.g. OECD 2003). ${ }^{1}$

Earnings were measured as the natural logarithm of the respondent's gross monthly earnings (in Finnish Marks (FIM), $€ 1 \approx 6$ FIM). The logarithmic transformation was necessary to normalize the income distribution. It also enables interpreting the effects of the independent variables in terms of percentage changes.

Our main independent variable of interest is obesity, defined as a dummy variable that is unity if the BMI of the respondent equals or exceeds 30 . This specification follows common practice in the field, as discussed earlier (e.g. Sarlio-Lähteenkorva \& Lahelma 2001; Laitinen et al. 2002). Based on our data, 11.8 per cent of male participants and 11.5 per cent female participants were obese.

We control for various variables that are related to both obesity and to labour market success. Education and age are key control variables. The ECHP education variable expresses the level of education in one of three levels; High education (ISCED 5-7), Middle education (ISCED 3), and Low education (ISCED 0-2). ${ }^{2}$ Following common practice, we include both linear and squared terms of age. Family status can also affect obesity and one's position in the labour market. Therefore, we control for marital 
status, number of children, and presence of a child under age 3. We also include selfassessed health (fair or good (reference) vs. bad or very bad), which is a commonly used summary health measure with good predictive power (Idler \& Benyamini 1997), as a control variable. Since obesity can also affect health, this variable could also have been introduced as an intervening variable (see below). Finally, we adjust for year dummies and geographical location, using the EU NUTS2-categorization. ${ }^{3}$

In the analysis of the effects of obesity on earnings, we also include various intervening variables-that are expected to be affected by obesity and also have an effect on labour market outcomes-in order to explain any obesity effects. Occupations were classified as non-manual labour ("white collar"), medium level non-labour ("medium level white collar"), professional manual labour ("professional workers") and manual labour ("workers"). In terms of professional status, we use the commonly division into "top-level", "medium level" and "managerial" positions. Tenure was measured as the time spent with the current employer.

The purpose of the control variables is to exclude obesity related impacts from other factors that influence success in labour market; whereas the intervening variables are used to explain effects of obesity on labour market sucess (e.g. Härkönen 2004, 55-56). So the main interest regarding the analysis relates to the parameter estimating the effects of obesity, as well as any possible changes in the parameter during different phases of the analysis. If the connection established early on in the analysis disappears after inclusion of the control variables, then the connection between obesity and success in the labour market is a result of variables influencing both factors. If the connection remains the same, it is possible to try to explain with the intervening variables: Which mechanisms produce the effects of obesity on labour market success?

\section{Methods}

We analyze the data by using random effects (RE) regression models, commonly used in analyzing panel data (e.g. Wooldridge 2002; Petersen 2004). In terms of data interpretation, these models are similar to normal regression models. The main benefit of random effects regression models, in comparison to normal regression models, is that they allow for more effective use of panel data. Random effects models take into account the nested structure of the data and thus provide correct estimates of the standard errors.

Furthermore, the RE model estimates the standard errors correctly, whereas normal regression model automatically do not. Random effects models do not, however, control for unobserved variables (Halaby 2004). In other words, estimated effects cannot be given a causal interpretation. Unfortunately it was not possible to control for unobserved factors, (with fixed effects model for instance) with the current data, as the necessary changes required for the estimation are too rare in the four year period. Thus, these models fit our purposes well. Mathematically they are equal to random effects multilevel models. (e.g. Hox \& Kreft 1994; Petersen 2004).

We analyze the effects of obesity on unemployment by using the RE logistic regression model and the same effects on respondent's earnings by using linear regression models. We evaluated these models separately between men and women, because the factors influencing success in the labour market differ between the genders. Estimation of the models was carried out by using the Stata 9.2 statistical software package's $x$ tlogit and $x$ treg commands. 


\section{Obesity effects on unemployment and earnings}

Table 1 shows a connection between obesity and earnings. The difference is bigger among women (approx. $€ 180$ per month) than men ( $€ 50$ per month). Moreover, no significant connection between men's obesity and unemployment was found, although unemployment is much higher among obese women than those of normal weight. Examining these differences serves as the basis for our analysis.

In Table 2 we look at the occurrence of obesity in relation to education, age, and region of residence. Obesity among women is clearly linked with education, as it is less common among highly educated than those with lower levels of education. The connection is stronger among women than men, as found in previous research. There is also a connection between obesity and age. Obesity is most common in the oldest age group (45-54 years). In addition, regional differences can be found, especially among women. Although the regional classification we have in use does not allow very detailed comparison between the regional differences, it seems that women's obesity is the rarest in

Table I Unemployment and gross monthly salary by obesity status

\begin{tabular}{lcccc}
\hline & \multicolumn{3}{c}{ Men } & \multicolumn{2}{c}{ Women } \\
\hline Monthly salary earnings, & $\mathrm{BMl} \geq 30$ & $\mathrm{BMl}<30$ & $\mathrm{BMl} \geq 30$ & $\mathrm{BMl}<30$ \\
\hline Finnish Mark (euro) & $\mid 2887,4$ & $\mid 3216,0$ & $8784, \mid$ & 9848,7 \\
\hline Unemployed (\%) & $(2 \mid 47,9)$ & $(2202,7)$ & $(\mid$ 464,0) & $(|64|, 5)$ \\
\hline
\end{tabular}

Source: European Community Household Panel, Finnish sample from 1998-200 I. Respondent's aged 25-54.

Table 2 Obesity, education, age, and region of residence (\%)

\begin{tabular}{|c|c|c|}
\hline & Men (BMI $\geq 30)$ & Women $(\mathrm{BMI} \geq 30)$ \\
\hline Low education & 12,5 & 16,4 \\
\hline Medium education & 11,3 & 13,9 \\
\hline High education & 11,3 & 7,7 \\
\hline Age group of 25-34 & 11,3 & 7,8 \\
\hline Age group of $35-44$ & 9,9 & 10,3 \\
\hline Age group of $45-54$ & 14,0 & 16,9 \\
\hline Uusimaa & 10,7 & 7,4 \\
\hline Southern Finland & 12,7 & 14,6 \\
\hline Eastern Finland & 11,3 & 14,0 \\
\hline Mid-Finland & 11,3 & $\mid 1,1$ \\
\hline Northern Finland & 12,4 & 12,9 \\
\hline Total & $1 \mid, 8$ & 11,5 \\
\hline
\end{tabular}

Source: European Community Household Panel, Finnish sample from 1998-200।. Respondents aged 25-54. 
the Southern region of Uusimaa (Nyland). Education, age, and the region of residence also have a clear connection with labour market success. Thus, control of such factors may help explain the relationship between obesity and labour market outcomes.

Table 1 shows how the unemployment rate among obese women is substantially higher than for other women, while for men there is no noticeable difference. In Table 3 we examine whether the results remain after adjusting for the control variables. We focus exclusively on obesity. Estimated effects of the other factors were as expected.

Table 3 shows that male obesity continues to have no impact on the risk of unemployment. The obesity estimate is not statistically significant and numerically it is close

Table 3 Obesity related impacts on unemployment, random effects logistic regression. Odds ratios $\left(e^{\beta}\right)$

\begin{tabular}{|c|c|c|}
\hline & Men & Women \\
\hline Obesity (BMI $\geq 30)$ & 1,078 & $2,266 * *$ \\
\hline High education & Ref. & Ref. \\
\hline Medium education & $1,901 *$ & $2,490 * * * *$ \\
\hline Low education & 3,191 米*** & $3,974 * * * *$ \\
\hline Age & $0,673 * *$ & $0,726 * *$ \\
\hline $\mathrm{Age}^{2}$ & I,005** & $1,004 *$ \\
\hline Number of children & 1,062 & 0,974 \\
\hline Youngest child $<3 \mathrm{v}$. & 1,511 & 1,456 \\
\hline Single & Ref. & Ref. \\
\hline Cohabitation & $0,439 * *$ & 0,863 \\
\hline Marriage & $0,108 * *$ & $0,434 * *$ \\
\hline Health fair/good & Ref. & Ref. \\
\hline Health bad & 2,088 & 1,152 \\
\hline Uusimaa & Ref. & Ref. \\
\hline Southern Finland & 1,127 & $1,890 *$ \\
\hline Eastern Finland & 3,539 ***** & $2,749 * *$ \\
\hline Mid-Finland & 1,742 & $2,822 * *$ \\
\hline Northern Finland & 3,40 I*** & $4,185^{* * * * *}$ \\
\hline 1998 & Ref. & Ref. \\
\hline 1999 & $0,611 *$ & 1,017 \\
\hline 2000 & 0,857 & 0,691 \\
\hline 2001 & 0,664 & 0,672 \\
\hline LL & $-971,709$ & $-1262,350$ \\
\hline$\chi^{2}$ & 130,07 & 101,84 \\
\hline $\mathrm{N}$ & 6490 & 6024 \\
\hline Number of respondents & 1840 & 1945 \\
\hline
\end{tabular}

Source: European Community Household Panel, Finnish sample from 1998-200I. Respondents aged 25-54. Significance levels: ${ }^{*} p<0,05$ *** $p<0,0$ I **** $p<0,00$ I. 
to one. Yet the effect of women's obesity is still noticeable. Unemployment risk among obese women is twofold compared to other women, even after adjusted for the effects of education, age, number of children and their age, marital status, health, region of residence and the year of data collection. Therefore, the connection between obesity and unemployment among women cannot be explained by their relatively weaker human capital, health, or regional variation. The results are in line with earlier studies (SarlioLähteenkorva \& Lahelma 1999, Quintana-Garcia \& Domeque 2006; Härkönen 2008). The impact of obesity on women's unemployment risk is approximately the same as the difference between a high level of education and a middle level of education.

How does obesity affect earnings? In Table 4 we asses the connection between obesity and the natural logarithm of earnings by using linear random effects regression models. In Table 1 we found that overweight men even enjoy slightly higher wages than other men, while the obese woman's euro was around 90 cents.

In table 4 we present regression models in which education, age, number of children and age, marital status, and health effects are adjusted for.

Table 4 Obesity effects on gross monthly salary, random effects linear regression. Standardized (B)

\begin{tabular}{|c|c|c|c|c|}
\hline & Men & Women & Women & Women \\
\hline & Model I & Model I & Model 2 & Model 3 \\
\hline Obesity (BMI $\geq 30$ ) & 0,013 & $-0,050$ * & $-0,037$ * & $-0,028$ \\
\hline Low education & Ref. & Ref. & Ref. & Ref. \\
\hline Medium education & $-0,142$ **** & $-0,169$ **** & 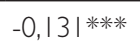 & $-0,137$ ***** \\
\hline High education & $-0,207$ ****** & $-0,197 * * * *$ & $-0,|5|$ *** & $-0,152$ ****** \\
\hline Age & $0,089^{* * * * *}$ & $0,087^{* * * * * *}$ & $0,05 \mid$ 米米 & 0,048 ****** \\
\hline $\mathrm{Age}^{2}$ & $-0,00 \mid$ ***** & $-0,00 \mid$ **** & $-0,00 \mid$ 米*** & $-0,00 \mid$ ***** \\
\hline Number of children & 0,013 & $-0,015$ & $-0,022 * * *$ & $-0,021 * * *$ \\
\hline Youngest child $<3 \mathrm{v}$. & $-0,037 *$ & $-0,045^{*}$ & $-0,011$ & $-0,021$ \\
\hline Single & Ref. & Ref. & Ref. & Ref. \\
\hline Cohabitation & 0,022 & $-0,040$ & $-0,015$ & $-0,019$ \\
\hline Marriage & $0,063^{* * *}$ & 0,010 & 0,001 & $-0,006$ \\
\hline Health fair/good & Ref. & Ref. & Ref. & Ref. \\
\hline Health bad & $-0,096 *$ & $-0,015$ & $-0,015$ & $-0,020$ \\
\hline Professional expert & & & Ref. & Ref. \\
\hline Mid-level white collar & & & $-0,160 * * * *$ & $0,158^{* * * * *}$ \\
\hline Skilled manual labour & & & $-0,105$ *** & $0,100 * *$ \\
\hline Semi-skilled manual labour & & & $-0,3||$ ******* & $-0,292 * * * *$ \\
\hline Professional status: Professional & & & Ref. & Ref. \\
\hline Professional status: Semi-professional & & & 0,035 ***** & $0,037^{* * * * * *}$ \\
\hline Professional status: Managerial & & & $0,102 * * * *$ & $0,108 * *$ \\
\hline Lenght of employment (in years) & & & & $0,007 * * * *$ \\
\hline
\end{tabular}




\begin{tabular}{|c|c|c|c|c|}
\hline & Men & Women & Women & Women \\
\hline & Model I & Model I & Model 2 & Model 3 \\
\hline Uusimaa & Ref. & Ref. & Ref. & Ref. \\
\hline Southern Finland & $-0, \mid 42$ ***** & $-0,158$ ***** & $-0,108 * * * *$ & $-0,|| 8 * * * *$ \\
\hline Eastern Finland & $-0,24 \mid$ ****** & $-0,|6|$ 米米米 & $-0,139$ ***** & $-0,135$ ****** \\
\hline Mid-Finland & $-0,199$ ***** & $-0,232 * * * *$ & $-0,217$ ***** & $-0,208$ **** \\
\hline Northern Finland & $-0,172 * * * *$ & $-0,159$ ****** & $-0,|| 8$ ****** & $-0,115$ ***** \\
\hline 1998 & Ref. & Ref. & Ref. & Ref. \\
\hline 1999 & 0,023 *** & 0,037 ******* & $0,034 * * * *$ & 0,036 **** \\
\hline 2000 & 0,080 ***** & $0,09 \mid$ ****** & 0,072 ***** & $0,074 * * * *$ \\
\hline 2001 & 0,130 ***** & $0,136 * * * *$ & $0,109 * * * *$ & 0,112 *⿻丷木**十 \\
\hline Standard & $7,562 * * * * *$ & 7,383***** & 8,221 **** & $8,3||$ 米*** \\
\hline$R^{2}$ & 0,196 & 0,170 & 0,310 & 0,337 \\
\hline N & 4699 & 4835 & 4396 & 4200 \\
\hline Number of respondents & 1749 & |83| & 1699 & 1622 \\
\hline
\end{tabular}

Source: European Community Household Panel, Finnish sample from 1998-200 I. Respondents aged 25-54.

Significance levels: * $p<0,05$ *** $p<0,0$ I **** $p<0,00$ I.

According to our first model, obesity does not have an affect on men's earnings: The estimate is positive, but not statistically significant. However, the gross monthly salary is 5 per cent lower among obese women than other women, after controlling for education, family situation and health. In practice this difference corresponds to a wage gap of about one third between the medium and highly educated, and about one fourth between the high and the low educated.

What can explain the differences? We try to answer this question in Models 2 and 3. As there are no significant differences in men's earnings, we focus solely on women. In Model 2 we adjusted for the effects of occupation and professional position. By doing this we observed that the earnings gap drops below 4 per cent. This indicates that the relatively lower wages among overweight women is partly explained by the occupations they hold. In Model 3 we also adjusted for tenure. ${ }^{4}$ People who have stayed with the same employer for a long time tend to get paid more. According to this model the earnings gap drops below 3 per cent. Furthermore, the estimate loses its statistical significance. In other words, obese women tend to have been with the same employer for a shorter time, which partially explains their lower earnings.

The results from Models 2 and 3 can be interpreted as indicating that overweight women tend to be selected for professions with lower salaries. In addition, their weaker labour market attachment is associated with lower earnings. Findings therefore suggest that obese women have more difficulties in finding employment (c.f. Härkönen 2008), and if they do, they have a tendency towards less well paid occupations, either voluntarily or because their chances of getting better-paid jobs are weaker as a result of labour market discrimination. 


\section{Conclusions: traditional or new gender policies?}

Being overweight is not only a significant health risk for more and more Finns, but also a potential source for socio-economic disadvantages. Obese women are more than twice as likely to be unemployed, as well as earn 5 per cent less than the other women, even after adjusting for key background factors. The relative stability of the estimated effects indicates, especially in terms of unemployment, that obesity has a clear impact on labour market success. Of course, endogeneity cannot be entirely ruled out. However, cumulative evidence suggests that obesity indeed affects labour market success in a causal manner. Since obesity is linked with other factors predicting weaker labour market success, it has cumulative effects on socio-economic disadvantage. Our results are thus in line with other Finnish and international research literature (e.g. Laitinen et al. 2002; Cawley 2004; Garcia \& Quintana-Domeque 2006). Compared to previous Finnish studies, our main contribution relates to the amount of control and intervening variables and on the more efficient panel data analysis. Obesity can be shown to have a real impact on the 25-54 year olds success in the Finnish labour market. However, these effects are very unevenly distributed between sexes, as well as among those in professionally different positions.

The results in this article cater for interesting socio-political interpretations. Firstly, the results reflect the Finnish labour market in an unpleasant way as women seem to be discriminated based on their physical characteristics. The obesity gap in female earnings was partly related to lower tenure and weaker professional positions of obese women. Earlier results suggest that obese women in Finland are in a weaker position in the competition for jobs, but do not differ in their job search behaviours (Härkönen 2008). This can explain why obese women not only have higher unemployment risks, but are also paid less due to their lower average tenure and less-favourable jobs they might end up having to accept. Although our results can potentially be explained by some unobserved mechanisms linking obesity to more adverse effects on women than on men, genderbiased discrimination of obese people appears as a plausible explanation our findings, as suggested by several other studies.

It is important to study why this is the case. Is it mainly due to employer discrimination, driven by sexist attitudes and old fashioned prejudices? Do employers see women's obesity (but not men's) as a signal of other undesired qualities? Discrimination and screening in the labour market are largely employability related phenomena. In both cases, however, it also about socio-cultural defect, which one would hope would get tackled soon in the name equal opportunity and equality.

Secondly, it is only appropriate to emphasize the fact that the impacts of obesity, in terms of our empirical findings, are especially interesting as obesity does not appear to be an issue in terms of men's success in the labour market. It is of course so that in the light of current scientific knowledge we cannot make very detailed conclusions on this matter. This only further emphasises the fact that understanding the obesity-related gender-specific effects still require plenty of further research.

Current societal trends, even in Finland, seem to indicate that obesity is becoming a new source of socio-economic inequality. It has an ever-increasing significance, especially in the current era where beauty and efficiency ideals are virtually ever present, via the different social media's (e.g. Harjunen 2004; Räsänen \& Wilska 2007). Weight control issues are part of this context, especially in the form of unhealthy diets 
and indifferent lifestyles among different population groups. Observations made in social science are theoretically pivotal as they point out many of the already existing structural defects within the society. Thus, the concern is not just about individual's health risks, although in many contexts the debate does not seem to get pass this point. Instead, it is about a phenomenon which is fundamentally tied to the functioning of modern society.

More and more jobs are expected to be created in the service sector in the coming years. Therefore it is predictable that more and more attention and pressure is directed towards appearance. Obesity is unlikely to be considered as a benefit in many service sector jobs. It is also possible that the importance of appearance will increase also among many of the traditional white collar professions. In the future, employer evaluations may focus more and more on the employer's social skills and team work abilities. Obesity may be seen as a negative quality in these types of situations, even if obesity in itself does not have effects on employee productivity.

Being able to identify the different characteristics connected with physical appearance will likely be an increasingly important factor when hiring for job positions in the future. At present, obesity-related negative socio-economic effects are mainly a concern for women, and especially for women who are professionally and economically in a weaker position. However, by looking at the statistics we can witness the increasing trend in BMI developments and these days almost half of the Finns can be classified as overweight (WHO 2010). It will be interesting to see what kind of future impacts this sort of development will have on both men and women's position in the Finnish labour market.

We believe that viewing obesity as a socio-economic defect will ultimately lead to some general interpretations of the current societal conditions. Men and women are valued differently in the Finnish and other Western labour market and it seems that physical appearance seems to play key role in this division of value. These manifestations of inequality appear to be stable, both structurally and time wise, even though they have become more and more visible through different individual factors.

\section{Literature}

Becker, G. S. (1975). Human Capital: A Theoretical and Empirical Analysis, With Special Reference to Education. Chicago: University of Chicago Press.

Brunello, G. \& D'Hombres, B. (2007). Does body weight affect wages? Evidence from Europe. Economics and Human Biology 5, 5-19.

Carr, D. \& Friedman, M. A. (2005). Is Obesity Stigmatizing? Body Weight, Perceived Discrimination, and Psychological Well-Being in the United States. Journal of Health and Social Behavior 46, 244-259.

Cawley, J. (2004). The Impact of Obesity on Wages. Journal of Human Resources 39, $451-474$.

Conley, D. \& Bennett, N. G. (2000). Is Biology Destiny? Birth Weight and Life Changes. American Sociological Review 65, 458-467.

Conley, D. \& Glauber, R. (2007). Gender, Body Mass, and Socioeconomic Status. In Bolin, K \& Cawly, J. (Eds): Advances in Health Economics and Health Services Research Vol. 17. The Economics of Obesity. (p. 255-278). Elsevier: Amsterdam.

Garcia, J. \& Quintana-Domeque, C. (2006). Obesity, Employment, and Wages in Europe. Advances in Health Economics and Health Services Research 17. 
Glass, C. M., Haas, S. A. \& Reither, E. N. (2010) The Skinny on Success: Body Mass, Gender and Occupational Standing Across the Life Course. Social Forces, 88, 4, 1777-1806.

Gossrow, N. \& Jeffrey, R. \& McGuire, M. (2001). Understanding Weight Stigmatization: A Focus Group Study. Journal of Nutrition Education 33, 208-214.

Halaby, C. N. (2004). Panel Models in Sociological Research: Theory into Practice. Annual Review of Sociology 30, 507-44.

Harjunen, H. (2004). Lihavuus, stigma ja sukupuoli. In Jokinen, Eeva \& Kaskisaari, Marja \& Husso, Marita (eds.): Ruumis töibin! Käsite ja käytäntö. (p. 243-262). Vastapaino: Tampere.

Hox, J. \& Kreft, I. (1994). Multilevel Analysis Methods. Sociological Methods \& Research $22,283-299$.

Härkönen, J. (2003). European Community Household Panel - ECHP. Lyhyt Esittely. Turun yliopiston sosiaalipolitiikan laitoksen julkaisuja C:9/2003. Turun yliopisto: Turku.

Härkönen, J. (2004). Kausaalinen päättely sosiologiassa. Teoksessa Räsänen, Pekka \& Ruonavaara, Hannu \& Kantola, Ismo (toim.): Kiistoja ja dilemmoja - Sosiologisen keskustelun vastakkainasetteluja. (p. 54-69). Kirja-Aurora: Turku.

Härkönen, J. (2007). Jobless Couples in Europe. Comparative Studies With Longitudinal Data. Doctoral Dissertation. Florence: European University Institute.

Härkönen, J. 2008. Labour Force Dynamics and the Obesity Gap in Female Unemployment in Finland. Research on Finnish Society 1, 3-15.

Idler, E.L. and Benyamini, Y. (1997). Self-Rated Health and Mortality: A Review of TwentySeven Community Studies. Journal of Health and Social Behavior 38, 21-37.

Johansson, E. \& Böckerman, P. \& Kiiskinen, U. \& Heliövaara, M. (2009) Obesity and labour market success in Finland: The difference between having a high BMI and being fat. Economics of Human Biology 7, 36-45.

Jokinen, E. (1997). Vihjeet. In E. Jokinen (eds.) Ruumiin siteet. Tekstejä eroista, järjestyksistä ja sukupuolesta. (p. 7-18). Tampere: Vastapaino.

Koivusilta, L. \& Rimpelä, A. \& Kautiainen, S. (2006). Health Inequality in Adolescence. Does Stratification Occur by Familial Social Background, Family Affluence, or Personal Social Position? BMC Public Health 6, 110.

Lahti-Koski, M. (2001). Body Mass Index and Obesity Among Adults in Finland. Trends and Determinants. Publications of the National Public Health Institute (KTL) A12/2001. KTL: Helsinki.

Laitinen, J. \& Power, C. \& Ek, E. \& Sovio, U. \& Järvelin, MR. (2002). Unemployment and Obesity Among Young Adults in a Northern Finland 1966 Birth Cohort. International Journal of Obesity 26, 1329-1338.

Lallukka, T. \& Laaksonen, M. \& Martikainen, P. \& Sarlio-Lähteenkorva, S. \& Lahelma, Eero (2005). Psychosocial Working Conditions and Weight Gain Among Employees. International Journal of Obesity 29, 909-915.

Mincer, J. (1974). Schooling, Experience, and Earnings. National Bureau of Economic Research: Cambridge (Mass.).

Morland, K. \& Wing, S. \& Diez Roux, A. \& Poole, C. (2002). Neighborhood Characteristics Associated with the Location of Food Stores and Food Service Places. American Journal of Preventive Medicine 22, 23-29.

OECD. (2005). OECD in Figures - 2005 edition. Paris: OECD. <http://www.oecd.org/docum ent/62/0,2340,en_2649_201185_2345918_1_1_1_1,00.html> (Accessed June 5, 2010).

OECD. (2003) OECD Glossary of Statistical Terms. <http://stats.oecd.org/glossary/detail. asp? ID=2791> (Accessed August 4, 2010).

Oswald, A. J. \& Powdthavee, N. (2007). Obesity, Unhappiness, and the Challenge of Affluence: Theory and Evidence. The Economic Journal 117, 441-449.

Pagán, J. A. \& Dávila, A. (1997) Obesity, Occupational Attainment, and Earnings. Social Science Quarterly 78, 756-770. 
Petersen, T. (2004). Analyzing Panel Data: Fixed- and Random-Effects Models. In Hardy, M. A. and Bryman, A. (eds.) Handbook of Data Analysis. (p. 331-345). Sage, London.

Pietinen, P. \& Vartiainen, E. \& Männistö, S. (1996). Trends in Body Mass Index and Obesity among Adults in Finland from 1972 to 1992. International Journal of Obesity 20, 114-120.

Puuronen, A. (2004). Rasvan tyttäret. Etnografinen tutkimus anorektisen kokemustiedon kulttuurisesta jäsentymisestä. Nuorisotutkimusverkoston julkaisuja 42. Nuorisotutkimusverkosto: Helsinki.

Reitner, E. N., Hauser, R. M \& Yang, Yang (2009) Do birth cohorts matter? Age-periodcohort analyses of the obesity epidemic in the United States. Social Sciences \& Medicine $69,1439-1448$.

Rooth, D-O (2008) Obesity, Attractiveness, and Differential Treatment in Hiring. Journal of human resources $44,3,710-735$.

Räsänen, P. (2003). In the Twilight of Social Structures. A Mechanism-Based Study of Contemporary Consumer Behaviour. Annales Universitatis Turkuensis Ser. B 263. University of Turku: Turku.

Räsänen, P. \& Wilska, T-A. (2007). Finnish Students’ Attitudes towards Commercialised Sex. Journal of Youth Studies 10, 557-575.

Sarlio-Lähteenkorva, S. \& Lahelma, E. (1999). The Association of Body Mass Index with Social and Economic Disadvantage in Women and Men. International Journal of Epidemiology 28, 445-449.

Sarlio-Lähteenkorva, S. \& Silventoinen, K. \& Lahelma, E. (2004). Relative Weight and Income at Different Levels of Socioeconomic Status. American Journal of Public Health 94, 468-472.

Smith, D. P. \& Buss, D. M. (1996). Strategic Self-Promotion and Competitor Derogation: Sex and Context Effects of Mate Attraction Tactics. Journal of Personality and Social Psychology 70, 1185-1204.

Toivonen, T. (1997) Food and Social Class. Journal of Consumer Studies and Home Economics 18, 329-347.

WHO. (2003). Diet, Nutrition, and the Prevention of Chronic Diseases. WHO Technical Report Series 916. WHO: Geneva.

WHO. (2010). WHO Global Database on Body Mass Index. <http://www.who.int/bmi/index.jsp> (Accessed 6 June, 2010).

Winship, C. \& Radbill, L. (1994). Sampling Weights and Regression Analysis. Sociological Methods and Research, 23, 230-257.

Wooldridge, J. M. (2002). Econometric Analysis of Cross Section and Panel Data. MIT Press, Cambridge (MA.).

\section{End note}

${ }^{1}$ According to this definition, the unemployed are defined as those who are currently "without work", "seeking work" and "currently available for work" (OECD Glossary of Statistical Terms 2003), whereas gainful employment within the last 7 days is defined as employment.

${ }^{2}$ EHCP does not recognize ISCED-level 4. In practice this level equals ISCED level 3 further education.

${ }^{3}$ NUTS2-classification reformed 1.1.2003 onwards. Classification criteria in our data are the following: Uusimaa, Southern Finland, Eastern Finland, Mid-Finland, and Northern Finland.

${ }^{4}$ We also experimented with other explanatory variables, such as employment sector (private/public, production/service). The results remained robust. Furthermore, they remained robust after restricting the analysis to cases with no missing observations. 